\title{
Uma nova espécie de Mimosa L. (Leguminosae, Mimosoideae) do Centro-Oeste do Brasil
}

\author{
Rosilene Rodrigues Silva ${ }^{1,3}$ e Ana Maria Goulart de Azevedo Tozzi ${ }^{2}$
}

Recebido: 12.01.2009; aceito: 31.03.2011

\begin{abstract}
A new species of Mimosa L. (Leguminosae, Mimosoideae) from Midwestern Brazil). A new species of Mimosa (Leguminosae, Mimosoideae, Mimosae) from Mato Grosso do Sul state, Midwestern Brazil, M. ferricola R.R. Silva \& A.M.G. Azevedo, is described and illustrated. Morphologically M. ferricola is related to M. gemmulata Barneby and to M. nothopteris Barneby, and belongs to Mimosa sect. Batocaulon DC. ser. Leiocarpae Benth.
\end{abstract}

Key words: Fabaceae, Mato Grosso do Sul, Mimosa ferricola, series Leiocarpae

RESUMO - (Uma nova espécie de Mimosa L. (Leguminosae, Mimosoideae) do Centro-Oeste do Brasil). Uma nova espécie de Mimosa (Leguminosae, Mimosoideae, Mimosae) do estado do Mato Grosso do Sul, Centro-Oeste do Brasil, M. ferricola R.R. Silva \& A.M.G. Azevedo, é descrita e ilustrada. Morfologicamente M. ferricola é relacionada com M. gemmulata Barneby e com M. nothopteris Barneby, e posicionada em Mimosa sect. Batocaulon DC. ser. Leiocarpae Benth.

Palavras-chave: Fabaceae, Mato Grosso do Sul, Mimosa ferricola, série Leiocarpae

\section{Introdução}

Mimosa L. é um gênero pertencente à família Leguminosae, subfamília Mimosoideae e é considerado o maior gênero da tribo Mimoseae Bronn (Luckow 2005), com cerca de 530 espécies (Simon 2008). Destas, $90 \%$ são americanas; o restante está distribuído na África e Ásia (Grether 2000). Nos neotrópicos, o gênero apresenta grande riqueza específica, sendo o Brasil Central considerado um dos maiores centros de diversidade do gênero (Barneby 1991, Grether 2000).

As espécies de Mimosa são herbáceas, subarbustivas, arbustivas, arbustivo-escandentes ou, raramente, arbóreas, armadas ou inermes. Caracterizam-se principalmente pelos frutos do tipo craspédio, com replo (réplum) persistente, mas também pelas folhas biparipinadas, com número variado de folíolos e com parafilídeos na base, pelas inflorescências de espigas globosas a cilíndricas, em racemos ou panículas, hermafroditas, unissexuais ou poligâmicas, pelas flores isostêmones ou diplostêmones, com cálice e corola trímeros a hexâmeros, estames livres ou unidos basalmente entre si, anteras sem glândulas no ápice do conectivo e ovário séssil ou subséssil.

De acordo com a classificação de Mimosa para a América, proposta por Barneby (1991), o gênero compreende cinco seções, Batocaulon DC., Calothamnos Barneby, Habbasia DC., Mimadenia Barneby e Mimosa L. Dentre estas seções, Mimosa sect. Batocaulon compreende cerca de 190 espécies agrupadas em 25 séries. A maior de suas séries é Mimosa ser. Leiocarpae Benth., representada por cerca de 27 espécies ocorrentes na América do Sul, principalmente no planalto brasileiro, Bolívia e Paraguai. A circunscrição da série Leiocarpae foi ampliada pela inclusão das espécies subordinadas à série Distachyae Britton \& Rose ex Barneby, de acordo com a proposta de Grether (2000). Esta série pode ser reconhecida pelas flores tetrâmeras em inflorescências espiciformes e pelos tricomas estrelados, simples e glandulares (Barneby 1991).

1. Vale/Complexo Corumbá, Gerência de Meio Ambiente, Rodovia Morro do Urucum s/nº Caixa Postal 221, 79301-970 Corumbá, MS, Brasil

2. Universidade Estadual de Campinas, Instituto de Biologia, Departamento de Biologia Vegetal, Caixa Postal 6109, 13083-970 Campinas, SP, Brasil

3. Autor para correspondência: rrodrigues98@ hotmail.com 
Embora estudos filogenéticos recentes, baseados em caracteres macromoleculares, têm sustentado o monofiletismo do gênero Mimosa, o mesmo não tem sido constatado em relação à maioria de suas categorias infragenéricas. Os resultados de análises filogenéticas baseadas em DNA de cloroplasto apontam Mimosa sect. Batocaulon ser. Leiocarpae como um táxon parafilético (Simon 2008), e carente de estudos taxonômicos e filogenéticos adicionais.

No estudo taxonômico das espécies de Leguminosae do Planalto Residual do Urucum, localizado nos municípios de Corumbá e Ladário, estado do Mato Grosso do Sul, região Centro-Oeste do Brasil (Silva 2006), verificou-se a existência de uma nova espécie de Mimosa, a qual está sendo aqui descrita e ilustrada.

\section{Resultados e Discussão}

Mimosa ferricola R.R. Silva \& A.M.G. Azevedo, $s p$. nov.

Tipo: BRASIL. Mato Grosso do Sul: Ladário, Serra do Rabichão, 26-II-2004, fl., R.R. Silva \& M.V. Silva 750 (holótipo UEC, isótipos COR, K).

Affinis M. gemmulatae, lobis corollae glandulis fulvis preditis similis, sed colore folioliorum, absentia spiculi interpinalis, magnitudine petioli, calyce non crateriformi, colore corollae et filamentorum et presentia setarum in replo differt. Etiam M. nothopteri similis absentia indumenti in facie adaxiali foliorum et praesentia glandulis in lobis corollae, sed absentia spiculi interpinalis, forma folioliorum, maginitudine calycis, colore corollae et filamentorum differt.

Figura $1 \mathrm{~A}-\mathrm{H}$

Arbusto arborescente, 2-2,5 m de altura; ramos denso-tomentosos, cinza-esbranquiçados, com glândulas amarelas, ca. 0,1 mm diâm., sésseis; nós armados com 2 acúleos infra-estipulares, castanhos ou vermelhos. Estípulas ca. $2 \mathrm{~mm}$ compr., lineares, caducas. Folhas com 6-14 pares de folíolos (pinas) e 9-33 pares de foliólulos (folíolos); foliólulos 1-3,2 × 0,3-1 mm, decrescendo em tamanho e número na ráquis do ápice em direção à base, estreito-elípticos a largo-elípticos, verdes, base obliquamente subtruncada, ápice obtuso, margem glandular-ciliada, brilhantes em ambas as faces, face abaxial esparso-pubescente ou glabra, crateriforme, com glândulas sésseis, ca. 0,2 mm diâm., lentiformes, amarelas, nervura mediana subcêntrica ou excêntrica; ráquila dos folíolos mais longos 5-6 cm compr., dos mais curtos, 1,5-4,5 cm compr., com glândulas amarelas; pecíolo ca. $4 \mathrm{~mm}$ compr., tomentoso ou glabrescente; peciólulo 1-1,3 mm compr. Inflorescências 2,9-5,5 cm compr., em espigas axilares. Flores monóclinas e estaminadas, 4-meras; brácteas ca. 0,4 mm compr., espatuladas, caducas, com glândulas lentiformes, caducas; cálice 4-angulado, 0,2-0,4 mm compr., campanulado, glabro, margem ciliolada; corola 1-2 mm compr., campanulada, creme, castanho-escura quando seca, lobos deltóides, deflexos no botão, reflexos na antese, pubescentes; glândulas da face externa dos lobos lentiformes, amarelas, caducas; estames 8 , filetes 4-5 mm compr., cremes, livres até a base, exsertos; ovário subséssil, densoviloso, com glândulas lentiformes diminutas, caducas; estiletes encurvados na porção mediana, glabros. Frutos tipo craspédio, sésseis, subsésseis a raramente estipitados, castanho-escuros, replo 2,8-4,5 cm compr., setuloso, articulados; artículos 4-7, pubescentes, com esparsas glândulas diminutas. Sementes ca. 0,4 mm compr., quadrangulares a subquadrangulares, castanho-escuras, levemente brilhantes, testa macia, glabra, com pleurograma aberto.

Parátipos: BRASIL. Mato Grosso do Sul: Ladário, Serra do Rabichão, 4-VII-2001, fr., A. Pott 9306 (CEN, CGMS, HMS, MBM, R); 21-X-2003, fr., R.R. Silva \& M.V. Silva 390 (HUEFS); 20-V-2004, fr., R.R. Silva \& M.V. Silva 960 (RB, SPF, UEC); 20IV-2004, fr., R.R. Silva \& M.V. Silva 871 (COR, K).

Mimosa ferricola foi encontrada apenas no município de Ladário, estado do Mato Grosso do Sul, região Centro-Oeste do Brasil. Esta espécie é pouco comum no local, estando associada à vegetação de Bancada Laterítica (lajedos). Na Bancada Laterítica ocorrem predominantemente plantas espinescentes, em particular espécies de Bromeliaceae e Cactaceae e, consequentemente, estas plantas têm sido consideradas pelos fazendeiros como prejudiciais aos rebanhos bovino e equiino. A ação antrópica neste local pode comprometer a sobrevivência da $M$. ferricola. Coletada com flores em fevereiro e com frutos em abril, maio, julho e outubro. $\mathrm{O}$ epíteto específico foi atribuído em função ao substrato rico em ferro, onde a espécie cresce.

Mimosa ferricola é caracterizada pelos ramos cinza-esbranquiçados, pelos folíolos brilhantes em ambas as faces, pela corola campanulada e de coloração creme, pelo replo setuloso e pela semente quadrangular. Está posicionada em $M$. sect. 


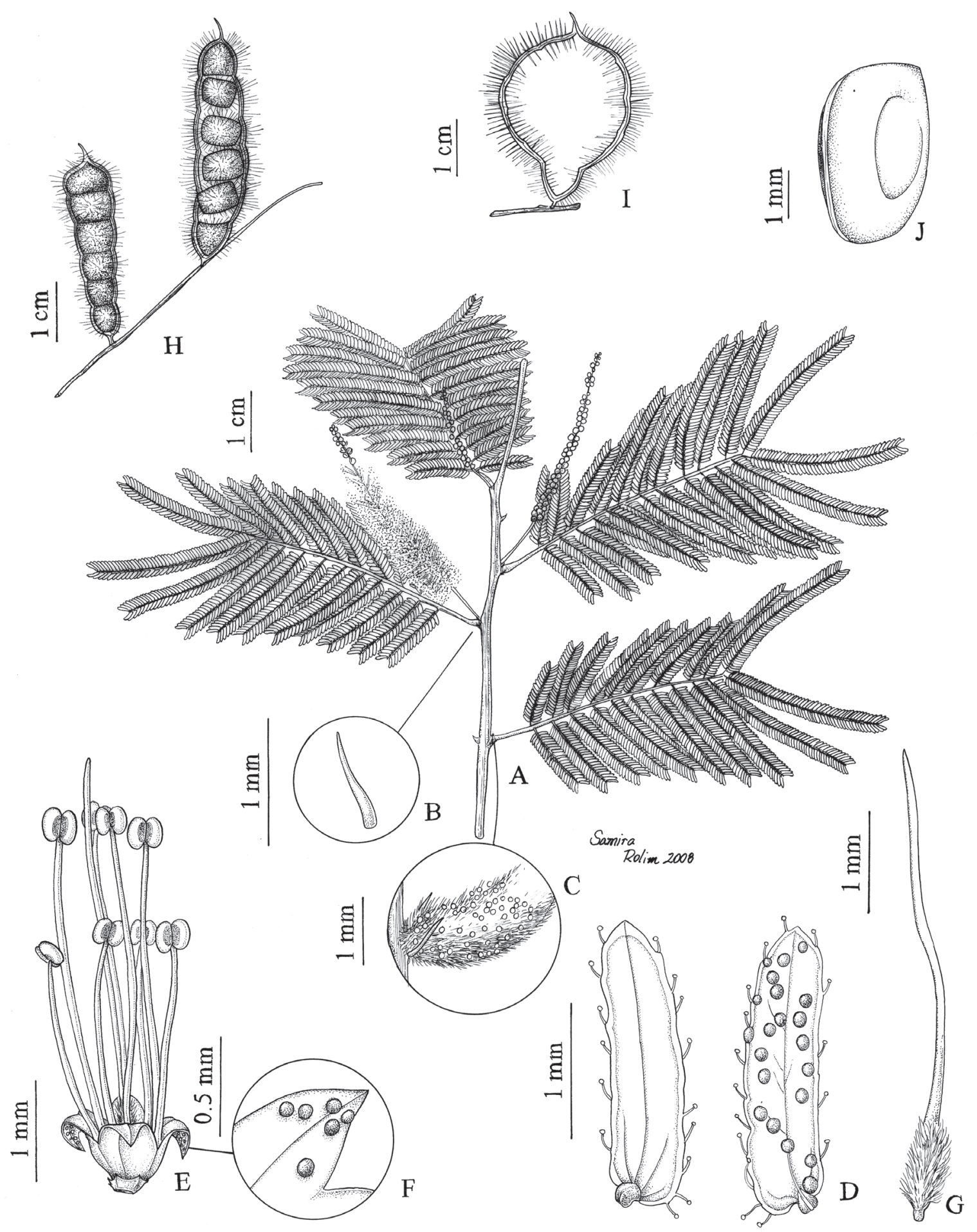

Figura 1. Mimosa ferricola R.R. Silva \& A.M.G. Azevedo. A. Ramo com inflorescências. B. Acúleo. C. Base do pecíolo com glândulas. D. Foliólulos em vista da face adaxial (à esquerda) e da face abaxial (à direita). E. Flor. F. Face externa da corola evidenciando glândulas. G. Gineceu. H. Pedúnculo com frutos. I. Replo. J. Semente. (A-G: R.R. Silva \& M.V. Silva 750, holótipo. H-J: R.R. Silva \& M.V. Silva 960, parátipo).

Figure 1. Mimosa ferricola R.R. Silva \& A.M.G. Azevedo. A. Branch with inflorescences. B. Spines. C. Base of the petiole with glands. D. Leaflets in view of the adaxial (at the left) and the abaxial side (at the right). E. Flower. F. Outer side of petal showing glands. G. Gynoecium. H. Fruits. I. Replo. J. Seed. (A-G: R.R. Silva \& M.V. Silva 750, holotype. H-J: R.R. Silva \& M.V. Silva 960, paratype). 
Batocaulon DC. ser. Leiocarpae Benth., pelo hábito arbustivo-arborescente, flores diplostêmones dispostas em espiga e frutos articulados.

Morfologicamente, as espécies mais próximas de Mimosa ferricola são M. gemmulata Barneby e M. nothopteris Barneby. As principais diferenças entre Mimosa ferricola e M. gemmulata estão na coloração verde de ambas as faces dos folíolos (bicolores em M. gemmulata), na ausência de estípula interpinal (presentes em $M$. gemmulata), na dimensão do pecíolo (2-16 $\mathrm{mm}$ compr. em M. gemmulata), no cálice com ausência de crateras (crateriforme em M. gemmulata), na coloração da corola creme (magenta ou creme-magenta em M. gemmulata), na coloração do filamento creme (magenta ou esbranquiçado em M. gemmulata) e na presença de setas no replo que estão ausentes em M. gemmulata. Já de Mimosa nothopteris, M. ferricola difere pela ausência de estípula interpinal, pela forma elíptica dos folíolos (oblongoobtusa em $M$. nothopteris), pela dimensão menor do cálice e pela coloração creme da corola e dos filetes (magenta em M. nothopteris).

\section{Agradecimentos}

Ao Sr. Márcio Venino da Silva pelo auxílio no trabalho de campo. À desenhista Samira Rolin, pela confecção da ilustração. Ao Dr. Tarciso S. Filgueiras, pela correção da diagnose latina. À Coordenação de
Aperfeiçoamento de Pessoal de Nível Superior (CAPES), pela concessão da bolsa de Doutorado ao primeiro autor. Ao Departamento de Botânica e ao Programa de Pós-Graduação em Biologia Vegetal, Universidade Estadual de Campinas, pelas facilidades para a execução deste trabalho. Ao Fundo de Apoio ao Ensino, à Pesquisa e à Extensão (FAEPEX/ UNICAMP), pelo auxílio às viagens de campo.

\section{Literatura citada}

Barneby, R.C. 1991. Sensitivae Censitae: a description of the genus Mimosa Linnaeus (Mimosaceae) in the New World. Memoirs of the New York Botanical Garden 65: 1-835.

Grether, R. 2000. Nomenclatural changes in the genus Mimosa (Fabaceae, Mimosoideae) in southern Mexico and Central America. Novon 10: 29-37.

Luckow, M. 2005. Tribe Mimoseae. In: G. Lewis, B.D. Schrire, B. Mackender \& M. Lock (eds.). Legumes of the World. Royal Botanic Gardens, Kew, pp. 163-183.

Silva, R.R. 2006. Leguminosae no Planalto Residual do Urucum, oeste do Pantanal do Mato Grosso do Sul, Brasil: inventário, taxonomia e similaridade florística. Tese de Doutorado, Universidade Estadual de Campinas, Campinas.

Simon, M.F. 2008. Systematics and evolution of Mimosa L. (Leguminosae) and the assembly of a Neotropical plant diversity hotspot. Doctoral Thesis, University of Oxford, Oxford. 